\title{
Resenha
}

Sandro Vinicius Sales dos Santos ${ }^{1}$

\section{Sobre a docência masculina na educação infantil}

RAMOS, Joaquim. Gênero na Educação Infantil: relações (im)possiveis para professores homens. Jundiaí: Paco Editorial, 2017. 176 p.

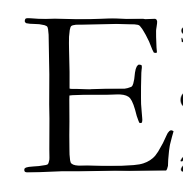

screver uma resenha não é tarefa simples. Trata-se, afinal, de um gênero textual que possui uma dupla função: por um lado, é um tipo de texto no qual se apresenta uma descrição minuciosa e, ao mesmo tempo, crítica de uma determinada produção (que, a título de exemplificação, pode ser um filme, uma peça teatral, um concerto musical ou um livro). Por outro lado, também é um estilo textual por meio do qual se convida alguém a conhecer a obra. Desse modo, escrever uma resenha é, em certo sentido, fazer um convite.

Pois bem! Neste texto, faço um convite aos/as profissionais da educação - principalmente aqueles/as que atuam em creches e pré-escolas - apresentando, para tanto, bons motivos para que eles/as conheçam o livro Gênero na Educaşão Infantil: relações (im)possiveis para professores homens, de autoria de Joaquim Ramos, lançado pela Paco Editorial.

Joaquim é professor da Rede Municipal de Ensino de Belo Horizonte (RME-BH) e atuou durante muito tempo como professor de creche comunitária. Igualmente, trabalhou como vice-diretor da primeira Unidade Municipal de Educação Infantil do município - a UMEI Juliana. Formado em letras, possui mestrado em Educação (ambos pela PUC Minas) e atualmente, cursa o doutorado latino-americano na Faculdade de Educação da Universidade Federal de Minas Gerais (FaE/UFMG). Não bastasse esta ampla trajetória profissional no campo educacional, Joaquim também foi premiado na $9^{a}$ edição do concurso "Construindo a igualdade de gênero" promovido pela Secretaria de Política das Mulheres (da Presidência da República), em parceria com o Conselho Nacional de Desenvolvimento Científico e Tecnológico (CNPq); a Secretaria de Educação Continuada, Alfabetização e Diversidade (SECADI); a Secretaria de Educação Básica (SEB) - ambas vinculadas ao Ministério da Educação (MEC) - e a ONU Mulheres. Esse prólogo,

'Doutor em Educação pela Faculdade de Educação da Universidade Federal de Minas Gerais (FAE/UFMG). Integrante do Núcleo de Estudos e Pesquisas Sobre Infância e Educação Infantil (NEPEl) da FaE/UFMG e do Grupo TElA (Territórios, Educação Integral e Cidadania) da FaE/UFMG. Professor adjunto do curso de Pedagogia da Faculdade Interdisciplinar em Humanidades da Universidade Federal dos Vales do Jequitinhonha e Mucuri - FIH/UFV JM. Docente do Programa de Pós-Graduação Stricto Sensu em Educação - Mestrado Profissional: Gestão de Instituições Educacionais - PPGED/UFVJM. E-mail: sandrovssantos@gmail.com 
por si só, já conduz qualquer pessoa interessada pelo assunto à leitura do livro. E mais: consente ao/à leitor/a compreender o lugar do qual fala Joaquim e que, indubitavelmente, lhe permite discutir, com muita propriedade, os ditos, os contraditos e os interditos que se cruzam no cotidiano de professores do sexo masculino que na atualidade se propõem a cuidar e educar crianças em instituições públicas de Educação Infantil. Contudo, ainda existem outros bons motivos que nos levam à leitura desta obra.

O livro resulta de estudo realizado pelo autor em nível de mestrado - que a partir de 2011 (ano de defesa da dissertação) se tornou referência obrigatória nas investigações sobre professores homens atuando no cuidado e educação de crianças pequenas. Desse modo, o fato de Joaquim transformar sua dissertação de mestrado em livro deve ser celebrado também pelo fato de fazer com que a obra adentre mais facilmente nas instituições de Educação Infantil, tornando-se, portanto, acessível também aos/às profissionais de creches e pré-escolas, pois no campo científico sua produção já apresenta grandes ressonâncias teóricas.

Seguindo na esteira das pesquisas sobre a presença de professores homens na Educação Básica, o livro de Joaquim Ramos é tributário de estudos e investigações anteriormente realizadas tanto no Brasil quanto no exterior, representadas pela produção teórica de Johan Scott (1995), Linda Nicholson (2000), Guacira Louro (1997) e de Rawein Connell - antes Robert Connell (1995), para citar alguns exemplos. No caso específico da produção científica brasileira, o autor segue uma tradição de pesquisa inaugurada pelo pioneirismo de Marília Pinto de Carvalho (1999) que analisa as ressonâncias das vozes masculinas no interior de uma profissão tipicamente feminina. Desse modo, o livro Gênero na Educação Infantil: relações (im)possiveis para professores homens se insere num grupo de estudos que visam não só analisar as relações de gênero na docência da Educação Infantil, mas também compreender em que medida as interfaces entre masculinidades e cuidado infantil contribuem para a produção de novas subjetividades. Assim, o livro de Joaquim Ramos se insere num rol de trabalhos acadêmicos exponenciais como os de Elizabete Franco Cruz (1998) e Debora Tomé Sayão (2005), que visam compreender as peculiaridades da docência masculina na Educação Infantil.

Se o conteúdo da obra é marcado pela expressividade e pela atualidade da temática, a forma como ela está organizada merece que se empregue igual atenção. O livro possui uma estrutura simples e didática que auxilia e favorece tanto quem está em campo investigando a temática das relações de gênero na docência de creches e pré-escolas, quanto quem está se aproximando dos estudos e pesquisas sobre masculinidades e Educação Infantil ou ainda quem se encontra em sala e se interessa pelo assunto. Logo na introdução, o autor descreve o processo de construção do objeto de estudo, bem como os objetivos de investigação. Evidencia também os itinerários metodológicos trilhados na interlocução com os professores do sexo masculino que atuam na Educação Infantil. No capítulo um, são apresentadas as lentes teóricas que sustentaram suas análises. No capítulo dois, o autor descreve as dores e as delícias vividas por três professores do sexo masculino em três instituições de Educação Infantil. No capítulo três, Joaquim discute a perspectiva de diferentes segmentos da comunidade educativa sobre a presença masculina na docência de creches e pré-escolas. Por último, ele tece suas considerações finais. 
Do ponto de vista teórico, o livro ancora-se nos estudos de gênero, em especial, nos estudos sobre masculinidade, aportes que permitiram ao autor não somente compreender o processo de inserção de homens na carreira docente, mas também as estratégias utilizadas por eles para manterem-se como professores de creches e pré-escolas. O autor afirma que é com a abertura de concursos públicos para o cargo de "educador infantil" - o que ocorre após a promulgação da Lei de Diretrizes e Bases da Educação Nacional (lei no 9394/96) - que os professores homens conseguem "furar as barreiras de gênero". É importante destacar que, diferentemente de outros níveis de ensino, a docência na e da Educação Infantil nasceu, efetivamente, como ocupação feminina e quando os homens passam também a ocupar esse espaço, são considerados como sujeitos fora do lugar, verdadeiros estranhos no ninho.

Joaquim desenvolveu sua investigação ao longo dos anos de 2009 e 2010. Neste período, ele identificou que o município de Belo Horizonte possuía aproximadamente 1800 profissionais de Educação Infantil e, deste quantitativo, apenas quatorze eram do sexo masculino. O autor, então, faz contato com todos esses professores e escolhe três para realizar entrevistas em profundidade.

Para compreender as nuances que envolvem a permanência desses profissionais nas instituições de cuidado e educação, Joaquim precisou desenvolver conceitualmente as noções de adaptação, transitoriedade e resistência, articulando-as nas análises do processo de inserção e dos mecanismos utilizados pelos docentes do sexo masculino para seguirem atuando na Educação Infantil. São três casos específicos: um primeiro professor que, segundo Joaquim, se encontrava, à época do estudo, finamente adaptado às práticas de cuidado e educação inerentes à docência dos bebês e crianças pequenas; um segundo docente que, por não se adaptar ao coletivo e às relações (pedagógicas, interpessoais, etc.) vividas nestes espaços, mudava repetidas vezes de instituição de Educação Infantil, o qual o autor descreve como um sujeito que construía sua identidade profissional pela via da transitoriedade e, por último, um terceiro professor que mantinha boas relações com as crianças e suas famílias, mas, não conseguia aprovação de seus pares (professoras de Educação Infantil) e que protagonizava verdadeiras "batalhas" no âmbito das relações profissionais - esse docente é definido por Joaquim como um sujeito que produzia sua identidade profissional pela via da resistência. Como forma de compreender a multiplicidade de sentidos em torno da docência masculina no interior das instituições de Educação Infantil, o autor, com acurada sensibilidade, ouviu também diferentes sujeitos presentes no cotidiano das instituições de cuidado e educação (pais, mães e familiares das crianças, coordenadoras pedagógicas, diretoras das instituições de Educação Infantil, etc.).

Talvez aqui resida uma das poucas limitações da obra: o fato de o autor ouvir representantes de diferentes segmentos da comunidade escolar deixando, contudo, de ouvir as crianças, principais destinatários das situações de cuidado e educação realizadas pelos professores do sexo masculino. Indubitavelmente, acredito que esta escuta - se feita do mesmo modo sensível com que o autor ouviu os diferentes sujeitos que conviviam cotidianamente com os professores homens, enriqueceria qualitativamente a obra. 
Aqui, é preciso cautela no uso dos vocábulos, uma vez que limitação é uma expressão que não pode ser confundida, em hipótese alguma, com demérito. Embora o estudo de Joaquim Ramos apresente tamanha envergadura e rigor teórico-metodológico, trata-se de uma investigação realizada em nível de mestrado - o que pressupõe um objeto de estudo precisamente delimitado, dadas às condições espaçotemporais de realização da pesquisa. Desse modo, ouvir as crianças seria algo inviável, pois se configuraria como outro estudo, em função das especificidades da investigação que aborda a perspectiva de meninos e meninas sobre diferentes dimensões da prática pedagógica por eles/as vividas no interior da instituição de Educação Infantil, o que envolve também as relações de gênero que atravessam a docência de creches e pré-escolas. Mesmo assim, a obra se constitui em documento revelador dos modos como os homens, na atualidade, se inserem nos cuidados e educação das crianças de até cinco anos em instituições de Educação Infantil.

Joaquim, com muita sagacidade, percebeu que existem pontos em comum na inserção dos professores homens, apesar de os três docentes com os quais ele conviveu no âmbito da empiria passarem por processos completamente distintos de investidura no cargo, o que também ocorreu em três contextos de atuação profissional bem diferentes. Assim, para além do estágio probatório - intrínseco ao serviço público - os professores do sexo masculino, segundo o autor, passam também por outro estágio: o período comprobatório - tempo de atuação no qual precisam "provar" que além de possuírem habilidades para cuidar e educar as crianças são sujeitos idôneos, de sexualidade ilibada e que, portanto, não oferecem riscos à integridade física e sexual de meninos e meninas.

Para o autor, o período comprobatório somente se encerra quando esses professores conseguem "provar" que possuem capacidade, habilidade e competência para cuidar e educar crianças e que não representam ameaças, nem tampouco são capazes de cometer abusos de qualquer natureza contra as mesmas. Na pesquisa, Joaquim constatou que a vigilância dos familiares das crianças e dos profissionais das instituições somente se atenua quando esses professores homens passam a ter o aval de todos/as ou de grande parte dos segmentos da instituição para exercer, com inteireza, o cargo para o qual foram aprovados em concurso público. Ou seja, para além da aprovação em concursos e do cumprimento do estágio probatório, conforme enfatizado pelo autor, esses sujeitos também são avaliados nas instituições a partir de múltiplos aspectos relacionados ao fazeres cotidianos vivenciados na relação tanto com os pares (professoras) quanto com as crianças e seus respectivos familiares.

$\mathrm{Na}$ visão do autor, o período comprobatório não ocorre de maneira simples e sem controvérsias: a aprovação desses homens para atuarem junto às crianças pequenas pode acontecer simultaneamente com todos os segmentos da instituição (família, professoras, direção), com alguns segmentos apenas e com outros não e, em alguns casos, pode até mesmo não ocorrer. Essa afirmação pode ser comprovada nas análises dos dados relacionados aos professores homens entrevistados por Joaquim Ramos: Natan, por exemplo, adaptou-se em curto período de tempo com todos os sujeitos que cotidianamente convivem na instituição de cuidados e educação; Tallys, por transferir-se constantemente de uma instituição para outra, está em constante período de adaptação e Cauã, apesar de ter a aceitação unânime das crianças e de seus 
familiares, enfrentava problemas de adaptação e aceitação nas relações com algumas colegas de trabalho e com a direção da instituição. Assim, o autor considera que para cada professor, dentro de suas especificidades e idiossincrasias, eram necessários tempos diferenciados para a adequação no espaço de atuação profissional: uns necessitam de mais tempo de adaptação e aprovação do coletivo institucional, outros menos tempo e outros não se adaptam. O fato é que todos, sem distinção, precisaram passar por esse estágio comprobatório antes de serem aceitos pelos diferentes sujeitos com os quais convivem cotidianamente nas instituições de Educação Infantil. Considera-se, portanto, que esse período de comprovação se conforma como um conjunto de rituais que possibilita a aceitação dos professores homens como parte constitutiva do corpo docente daquelas instituições. Ritos que acontecem nas temporalidades, nos espaços e nas relações travadas por eles com as famílias, com as demais profissionais da instituição e, inclusive, com as crianças. Dessa maneira, somente após a constatação de que esses sujeitos (professores homens) são idôneos, possuem capacidade, competência e uma sexualidade "acima de qualquer suspeita", recebem então o aval para atuarem junto às crianças sem tanta vigilância e tantos receios, conseguindo, dessa maneira, superar essa etapa de adaptação e serem aprovados pelo olhar de diferentes seguimentos que compõem o coletivo das instituições de Educação Infantil.

Cabe ressaltar que o contato com os profissionais de Educação Infantil do sexo masculino que, naquele momento, atuavam na Rede Municipal de Ensino de Belo Horizonte, possibilitou que Joaquim compreendesse como as identidades de gênero desses sujeitos atravessavam suas condições de trabalho. Segundo ele, vários docentes, ao tomarem posse dos cargos públicos de professor de Educação Infantil, foram encaminhados para funções que atuariam sob a vigilância constante de outros profissionais. Os professores de sexo masculino eram colocados na função de professor de apoio, na regência das turmas de crianças maiores ou como responsáveis pela "educação física", pelas oficinas de artes, de informática ou qualquer outra linguagem que o distanciassem das práticas de cuidado e, mais precisamente, os afastassem do contato com os corpos das crianças.

Este panorama apresenta elementos que, indubitavelmente, convidam os/as profissionais da educação, principalmente àqueles/as sensíveis às questões da diversidade e que lutam, cotidianamente, pela equidade entre homens e mulheres, meninos e meninas, a conhecerem a obra. Acredito, portanto, que existem motivos de sobra para ler Gênero na Educação Infantil: relações (im)possiveis para professores homens.

\section{Referências bibliográficas}

CARVAlHO, Marília Pinto de. No coração da sala de aula: gênero e trabalho docente nas séries iniciais. São Paulo: Xamã, 1999.

CONNELL, Robert W. Políticas da masculinidade. Educação e Realidade. Vol. 20 (2), jul/dez. 1995, p. 185-206. 
CRUZ, Elizabete Franco. "Quem leva o nenê e a bolsa?": o masculino na creche. In: ARILHA, Margareth; RIDENTI, Sandra G. Unberhaum; MEDRADO, Benedito (Orgs.). Homens e masculinidades: Outras palavras. São Paulo: ECOS/Ed. 34, 1998. p. 51-77

LOURO, Guacira Lopes. Gênero, sexualidade e educação: uma perspectiva pós-estruturalista. $8^{a}$ ed. Petrópolis: Vozes, 1997.

NILCHOLSON, Linda. Interpretando o gênero. Estudos Feministas, vol. 8, nº 2, 2000. p. 9- 42.

SAYÃO, Deborah Thomé. Relações de gênero e trabalho docente na educação infantil: um estudo de professores em creches. Tese (Doutorado) - Universidade Federal de Santa Catarina, Centro de Ciências da Educação, Florianópolis, 2005.

SCOTT, Joan W. Gênero: uma categoria útil de análise histórica. Educação e Realidade, vol. 20, (2), jul/dez. 1995. 